\title{
Flow Separation in Rocket Nozzles, a Simple Criteria
}

\author{
Ralf H. Stark ${ }^{*}$ \\ German Aerospace Center, Lampoldshausen,D-74239, Germany
}

\begin{abstract}
Cold and hot flow tests were conducted to investigate the flow separation in rocket nozzles. The results are presented. A separation data base including a wide range of literature data is established to evaluate the influence of propellant combination and nozzle design on flow separation. As a result a simple separation criteria is suggested.
\end{abstract}

\section{Nomenclature}

$\begin{array}{ll}p & =\text { pressure } \\ c_{f} & =\text { friction coefficient } \\ M a & =\text { wall Mach number } \\ M a_{d e s} & =\text { design Mach number } \\ \kappa & =\text { adiabatic exponent } \\ \theta & =\text { deflection angle } \\ \sigma & =\text { oblique shock angle } \\ u, U & =\text { velocity } \\ \delta & =\text { boundary layer thickness } \\ \delta^{*} & =\text { displacement thickness } \\ \delta^{* *} & =\text { momentum loss thickness } \\ a & =\text { ambient } \\ c & =\text { combustion chamber } \\ p & =\text { plateau } \\ w & =\text { nozzle wall } \\ e & =\text { exit area } \\ O & =\text { total condition } \\ \infty & =\text { edge of boundary layer } \\ \text { sep } & =\text { incipient separation } \\ T I C & =\text { truncated ideal contour } \\ T O P & =\text { thrust optimized parabola } \\ \text { DLR } & =\text { German Aerospace Center }\end{array}$

\section{Introduction}

$\mathrm{T}$ The design of today's launchers has changed from a classical tandem to a parallel configuration and the main stage engine therefore has to fulfill a wider range of operation conditions during ascent from sea-level to high altitude. A significant payload gain can be achieved if the main stage engine features a high specific impulse. As its contribution to the launchers total sea-level thrust, compared to the boosters, is of minor importance its nozzle is designed to be just full flowing under sea-level conditions to avoid flow separation resulting in undesired side loads. For that reason designing and test engineers need an easy to implement tool to estimate the separation location.

DLR performed test series to investigate the flow separation in rocket nozzles ${ }^{10,14,19,29}$ under various conditions like cold or hot flow, with and without film cooling. Of interest are the position of the separation, its length, its flow structure, its fluctuating nature and its increased heat load. Methods of flow separation visualization were evaluated and developed. Comparing the obtained flow separation data to values of common separation criteria a difference was observed. An upgraded separation data base combined with the obtained test data is used to define a simple separation criteria.

\footnotetext{
${ }^{*}$ Head of Nozzle Group, Department of Technology, D-74239 Lampoldshausen, Langer Grund, AIAA Member
} 


\section{Experimental Program}

Two exemplary test campaigns illustrate the investigation of flow separation and its visualization.

\section{A. Cold Flow Tests}

A test campaign was conducted to evaluate the capability of the optical pressure measurement method PSP (Pressure Sensitive Paint) to detect the location of flow separation ${ }^{30}$. The subscale cold flow tests were performed at test facility P6.2 $2^{17}$ using dry nitrogen as operating gas. The advantage of nitrogen compared to air is the absence of water vapor that tends to condense. Nitrogen can be easily modeled in attendant CFD calculations as a perfect gas.

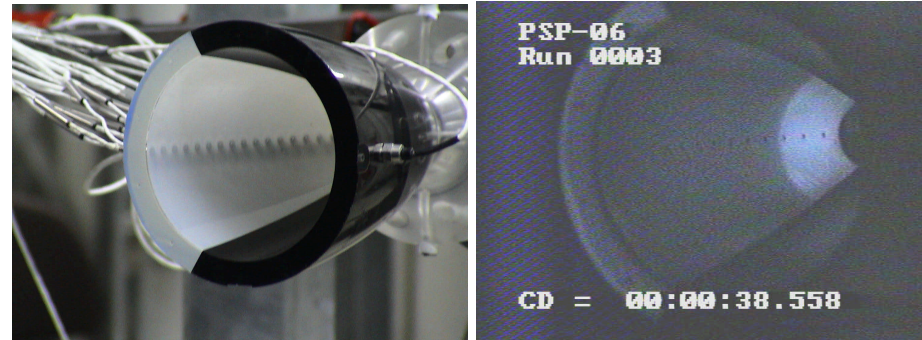

Figure 1. PSP test specimen (left), test run (right)

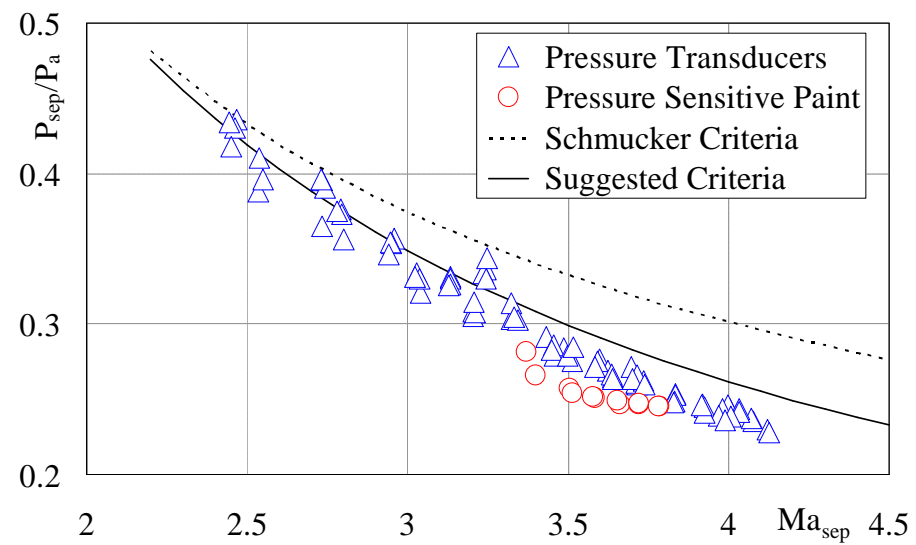

Figure 2. Comparison of wall pressure and PSP data

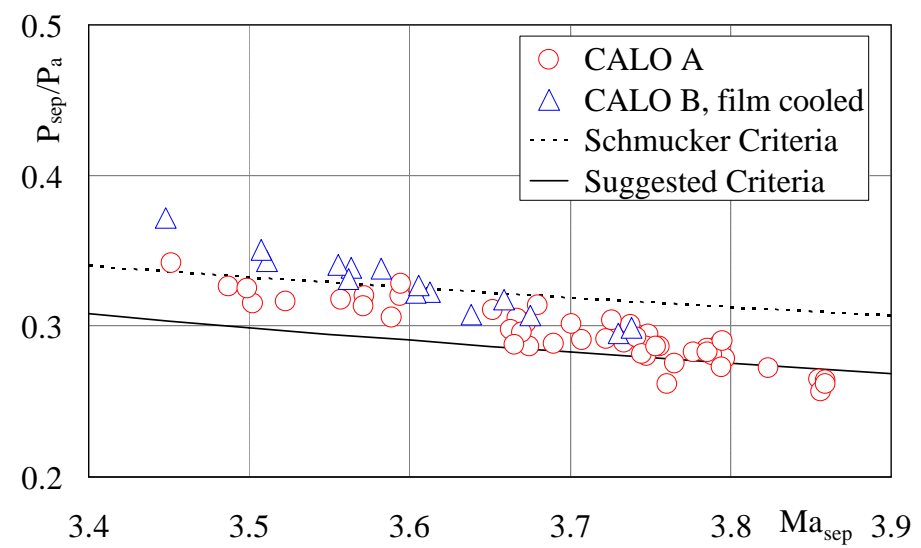

Figure 3. Flow separation with and without film-cooling
PSP bases on the physical properties of luminophores: Activated by light these organic molecules can achieve a higher energetic level. Luminophores return to their basic level by emitting light (fluorescence). The deactivation can also be effected by collisions of suitable molecules like oxygen. In this case the luminophores react with phosphorescence.

During test the region of the attached nitrogen flow pronounces bright (fig. 1), whereas the separated backflow region clouds. The intensity change marks the separation of the boundary layer, fading into the shear layer of the free jet. In combination with the constant vacuum wall pressure profile $\left(\mathrm{P}_{\mathrm{w}} / \mathrm{P}_{0}\right)$ a related wall pressure can be obtained.

The test data evaluation showed that PSP detects the downstream border of the fluctuating separation zone. Compared to wall pressure measurements, where the lowest value determines the position of the incipient separation (fig. 8), PSP overestimates the location of the flow separation (fig. 2).

\section{B. Hot Flow Tests}

In cooperation with EADS ST and Volvo Aero Corporation hot-firing tests were conducted at test facility $\mathrm{P} 8{ }^{15}$. The objective was to establish a data base of wall pressure and wall heat flux for separated nozzle flows. Three configurations were tested, including regenerative and film cooled nozzles. The tests were performed with hydrogen-oxygen mixture ratios from 5 to 7.6 and combustion chamber pressures up to $11.5 \mathrm{MPa}$.

\section{Separation data base}

The obtained cold and hot gas data as well

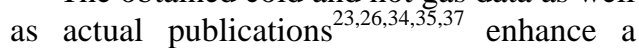
separation data base that was introduced by M. Frey ${ }^{11}$, including a wide literature survey ${ }^{2,3,6,8,9,13,20,24,32,36}$. 


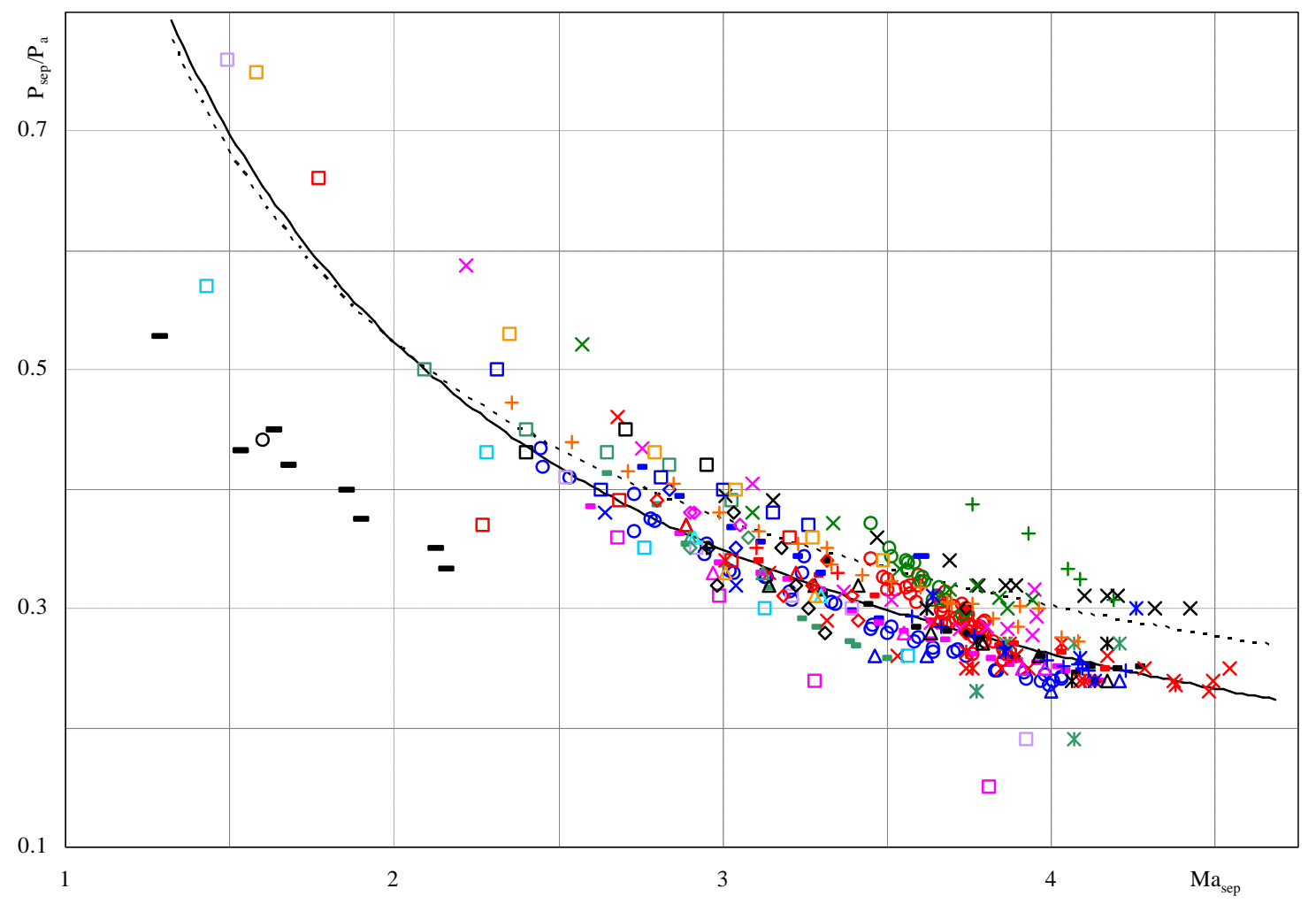

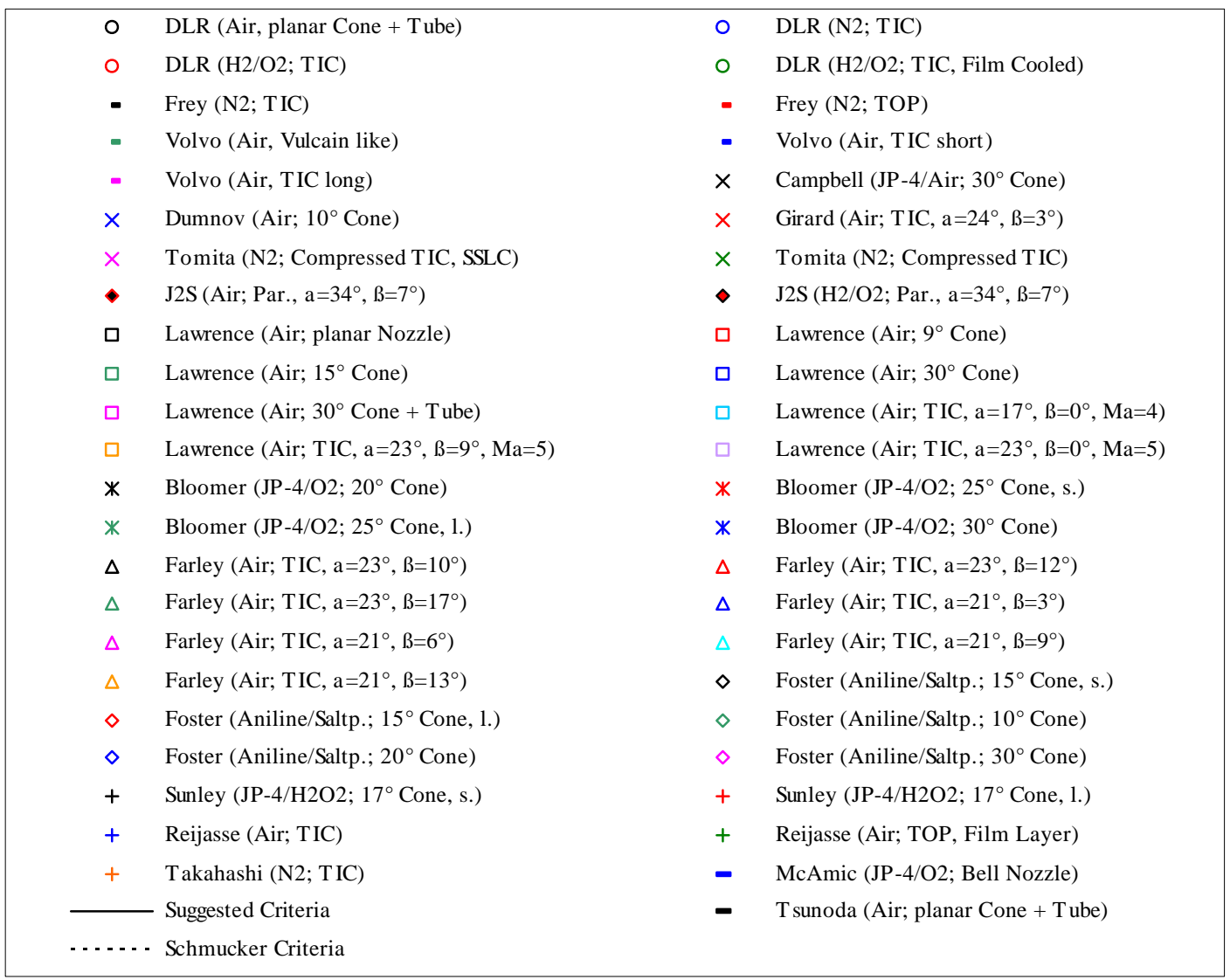

Figure 4. Separation data base

American Institute of Aeronautics and Astronautics 


\section{Discussion of Results}

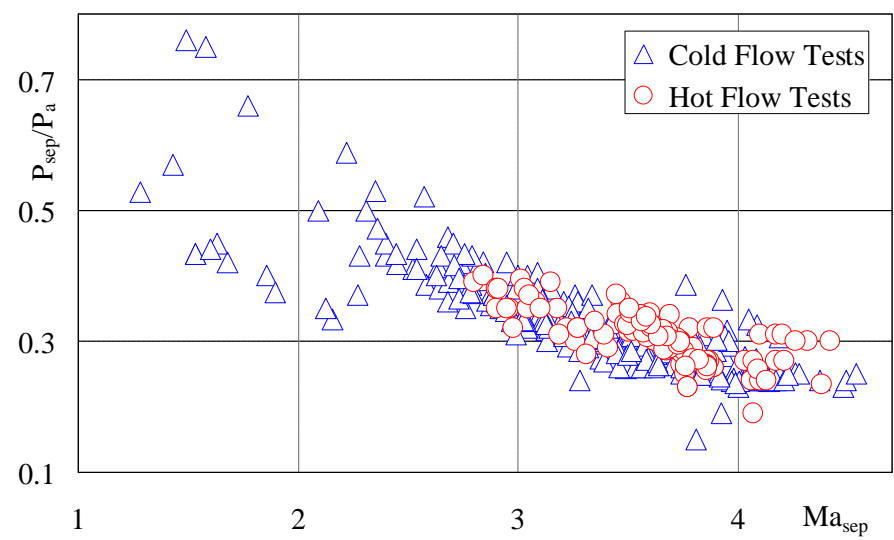

Figure 5. Cold and hot flow tests

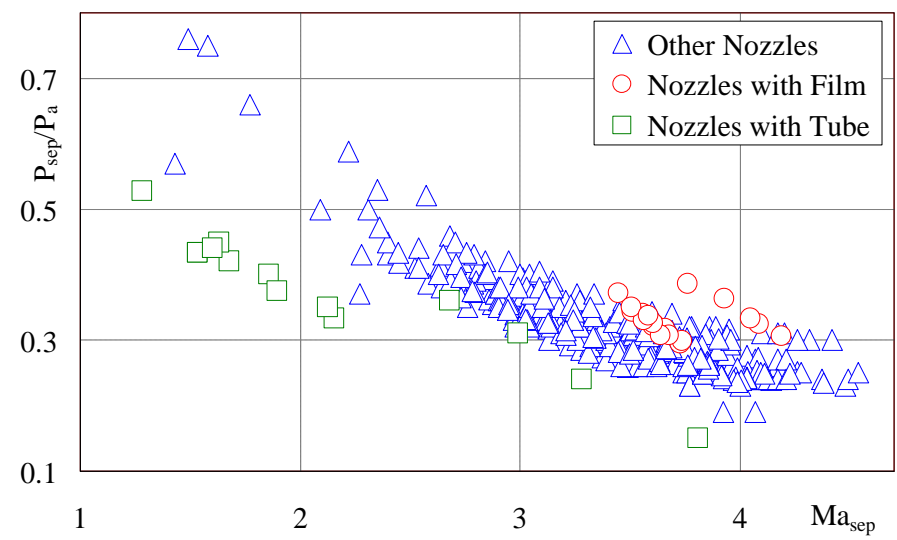

Figure 6. Film layer injection and attached tubes

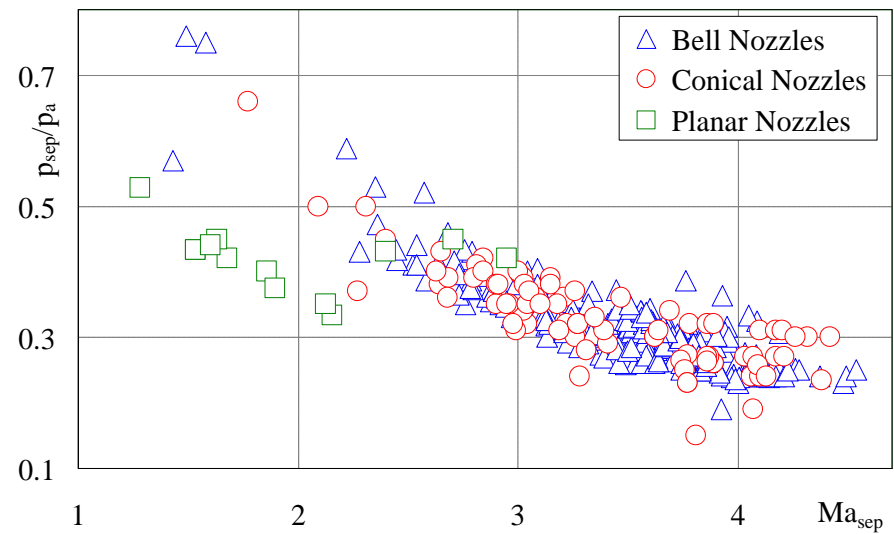

Figure 7. Nozzle design
The obtained cold gas test data (fig. 2) clearly fall below the expected trend and illustrate that common separation criteria like Schmucker's under predict the separation location. The hot gas data differ less but show an increasing difference with increasing wall Mach number $\mathrm{Ma}_{\text {sep }}$ too (fig. 3). The hot gas separation is superimposed by total pressure fluctuations causing a comparatively high variance of wall pressure data $p_{\text {sep }} / p_{a}$. This interaction is damped if a cooling film is injected. The data also point out that this film causes a premature separation. With proceeding evolution the film looses its efficiency and the flow separation normalizes.

Examining the data base the distribution of hot and cold flow data don't differ (fig. 5), except a small region around Mach 3.5 where data are dominated by the obtained hot gas data. The wall Mach number reproduces the influence of the adiabatic exponent $\kappa$ (and therefore the propellant combination) on the separation location in a sufficient manner.

In Fig. 6 the data are split up to visualize the influence of injected film layers and attached tubes. Apparently attached tubes cause a delayed separation. Especially Tsunoda's data differ. These data were verified using a small blow down wind channel build up for DLR education purpose. Its planar conical nozzle is three times smaller scaled than Tsunoda's setup. It was enhanced with a flat plate to achieve a tube like characteristic. The spacing of the available wall pressure sensors allows only one measuring point in the relevant Mach number interval. This single data point overlaps with Tsunoda's data.

An inverse influence on separation can be observed for film layers. As already mentioned the obtained hot gas data indicate a premature separation. This is verified by the cold flow data of Reijasse ${ }^{26}$. A comparable film layer influence is reported by Dumnov ${ }^{6}$ and well known from Europe's Vulcain 2 rocket engine.

An influence of the nozzle design on separation is not given (fig. 7).

Based on the data of fig. 4 the following separation criteria is suggested:

$$
\frac{p_{\text {sep }}}{p_{a}}=\frac{\Pi}{3 \cdot M a_{\text {sep }}}
$$

Where $\mathrm{p}_{\mathrm{a}}$ is the ambient pressure, $\mathrm{p}_{\text {sep }}$ is the wall pressure of the incipient separation and $\mathrm{Ma}_{\text {sep }}$ the related wall Mach number. 


\section{Conclusions}

Cold as well as hot flow subscale tests were conducted and presented. The obtained separation location data don't match with the expected values. For this reason an existing separation data base was enhanced to setup a separation criteria. The data show no evident influence of propellant combination or basic nozzle design on flow separation. The separation is affected by attached tubes and injected film layers.

Flow separation is a result of adaptation on ambient conditions. Even though this adaptation can be divided in two regions (the oblique shock recompresses the wall pressure $p_{\text {sep }}$ to plateau pressure $p_{p}$, followed by a system of recompression waves in the separated backflow region where plateau pressure $p_{p}$ is adapted to ambient condition $p_{a}$, fig. 8) it is not necessary to establish a separation criteria that considers this dichotomy, as suggested by some authors $1,4,5,11,16,18,20,25,33$. For designing purpose it is sufficient to derive the lowest achievable wall pressure for given system parameter like ambient pressure $\mathrm{p}_{\mathrm{a}}$, total pressure $\mathrm{p}_{0}$ and nozzle contour. The suggested separation criteria fulfils this requirement.

As an appendix some separation criteria are given.

\section{Appendix}

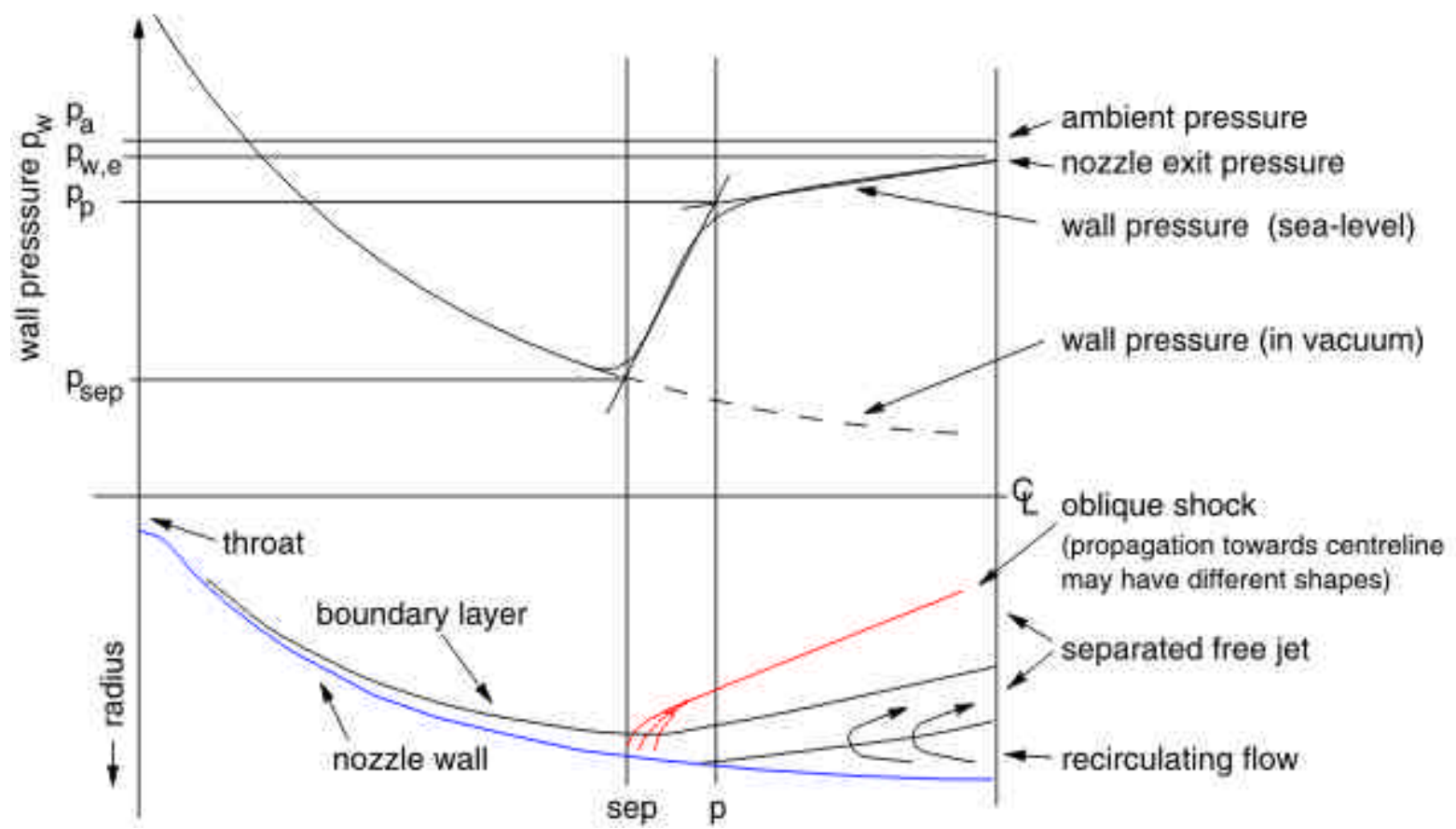

Figure 8. Free Shock Separation in over-expanding rocket nozzles (taken from Ref.11) 


\begin{tabular}{|c|c|}
\hline $\begin{array}{l}\text { Arens \& } \\
\text { Spiegler }\end{array}$ & $\frac{p_{\text {sep }}}{p_{p}}=\frac{\left[1+\frac{\kappa-1}{2} M a_{\text {sep }}^{2}\left(1-k_{A}^{2}\right)\right]\left\{0.5 M a_{\text {sep }}^{2}\left[(\kappa+1) k_{A}^{2}-\frac{(\kappa-1)^{2}}{\kappa+1}\right]-\frac{\kappa-1}{\kappa+1}\right\}^{\frac{1}{\kappa-1}}}{\left[\frac{\kappa+1}{2} M a_{\text {sep }}^{2} \cdot k_{A}^{2}\right]^{\frac{\kappa}{\kappa-1}}}, \mathrm{k}_{\mathrm{A}}=\mathrm{u} / \mathrm{U}_{\infty}$ \\
\hline $\begin{array}{l}\text { Crocco- } \\
\text { Probstein }\end{array}$ & $\begin{array}{l}\frac{p_{p}-p_{\text {sep }}}{\kappa \cdot p_{\text {sep }}}\left[\frac{k_{1 \text { sep }}}{M a_{\text {sep }}^{2}}+\frac{\kappa-1}{2}\left(k_{1 s e p}-1\right)\right]= \\
1-\frac{k_{2 p}}{k_{2 s e p}} \sqrt{\left(\frac{2}{\kappa-1}\right)} \cdot \frac{1}{M a_{\text {sep }}} \sqrt{\left(1+\frac{\kappa-1}{2} M a_{\text {sep }}^{2}-\left(\frac{\kappa+1}{\kappa-1}+\frac{p_{p}}{p_{\text {sep }}}\right) /\left(\frac{\kappa+1}{\kappa-1}+\frac{p_{\text {sep }}}{p_{p}}\right)\right)} \\
k_{1}=1 /\left(1-\frac{\delta^{*}}{\delta}-\frac{\delta^{* *}}{\delta}\right) \\
k_{2}=\left(1-\frac{\delta^{*}}{\delta}-\frac{\delta^{* *}}{\delta}\right) /\left(1-\frac{\delta^{*}}{\delta}\right)\end{array}$ \\
\hline $\begin{array}{l}\text { Donaldson } \\
\text { \& Lange }\end{array}$ & $\frac{p_{p}}{p_{s e p}}=1+k_{3} \cdot \frac{\kappa}{2} \cdot M a_{s e p}^{2} \cdot c_{f}, \mathrm{k}_{3}:$ constant determined from analysis of experimental data \\
\hline Frey & $\frac{p_{\text {sep }}}{p_{p}}=\left(1+\frac{2 \cdot \kappa}{\kappa+1} \cdot\left[M a_{\text {sep }}^{2} \cdot \sin ^{2}\left(44.5^{\circ}-4.7^{\circ} \cdot M a_{\text {sep }}\right)-1\right]\right)^{-1}$ \\
\hline $\begin{array}{l}\text { Kalt \& } \\
\text { Badal }\end{array}$ & $\frac{p_{\text {sep }}}{p_{a}}=\frac{2}{3} \cdot\left(\frac{p_{c}}{p_{a}}\right)^{-\frac{1}{5}}$ \\
\hline Kudryavtsev & $\frac{p_{a}}{p_{p}}=1+\left(\frac{0.192}{\sin \alpha}-0.7\right)\left(1-\frac{M a_{\text {sep }}}{M a_{\text {des }}}\right) ;$ Proposed for air in conical nozzles, $\alpha<15^{\circ}$ \\
\hline Lawrence & $\frac{M a_{p}}{M a_{\text {sep }}}=0.8$ \\
\hline Mager & $\frac{p_{\text {sep }}}{p_{a}}=\left[1+\left(\frac{\kappa}{2} M a_{\text {sep }}^{2} \frac{1-k}{1+\frac{\kappa-1}{2} M a_{\text {sep }}^{2}}\right)\left(1+0.328 \frac{\kappa \cdot M a_{\text {sep }}^{2} \cdot k^{2} \cdot \Theta}{1+\frac{\kappa-1}{2} M a_{\text {sep }}^{2} \cdot k^{2}}\right)\right]^{-1} ; \mathrm{k}=\mathrm{Ma}_{\mathrm{p}} / \mathrm{Ma}_{\text {sep }}$ \\
\hline Östlund & $\begin{array}{l}\sigma=-3,764^{\circ} \cdot M a_{\text {sep }}+42,878^{\circ} \\
\theta=1,678^{\circ} \cdot M a_{\text {sep }}+9,347^{\circ}\end{array}$ \\
\hline Schilling & $\frac{p_{\text {sep }}}{p_{a}}=0.583 \cdot\left(\frac{p_{c}}{p_{a}}\right)^{-0.195} ;$ Suggested for short bell nozzles \\
\hline Schmucker & $\frac{p_{\text {sep }}}{p_{a}}=\left(1.88 \cdot M a_{\text {sep }}-1\right)^{-0.64}$ \\
\hline $\begin{array}{l}\text { Suggested } \\
\text { Criteria }\end{array}$ & $\frac{p_{\text {sep }}}{p_{a}}=\frac{\Pi}{3 \cdot M a_{\text {sep }}}$ \\
\hline Summerfield & $\frac{p_{\text {sep }}}{p_{a}}=0.35 \ldots . .4$ \\
\hline
\end{tabular}




\begin{tabular}{|l|l|}
\hline Tagirov & $\frac{p_{p}}{p_{s e p}}=\left(\sqrt{A_{1}^{2}+A_{2}\left(1+\frac{\kappa-1}{2} M a_{\text {sep }}^{2}\right)}-A_{1}\right) / A_{2}$ \\
& $A_{1}=\frac{\kappa+1}{4}\left(A_{3}-1\right) \cdot M a_{s e p}^{2}$ \\
& $A_{2}=1+\frac{\kappa-1}{2} \cdot A_{3} \cdot M a_{\text {sep }}^{2}$ \\
& $A_{3}=\left(\frac{M a_{p}}{M a_{s e p}}\right)^{2}$ \\
\hline Zukoski & $\frac{p_{s e p}}{p_{a}}=\frac{2}{M a_{s e p}+2} ;$ Forward-Facing Step \\
\hline
\end{tabular}

\section{Acknowledgments}

The author would like to thank his colleagues of the 'Flow Separation Control Device' group ${ }^{12}$ (CNES, DLR, EADS ST, ESTEC, ONERA, LEA at Portiers, Snecma, Volvo Aero Corporation) for fruitful scientific exchanges.

\section{References}

${ }^{1}$ Arens M., and Spiegler E., "Shock-Induced Boundary Layer Separation in Overexpanded Conical Exhaust Nozzles", AIAA Journal, Vol. 1, No. 3, page 578-581, 1963.

${ }^{2}$ Bloomer H.E., Antl R.J., and Renas P.E., "Experimental Study of Effects of Geometric Variables on Performance of Conical Rocket-Engine Exhaust Nozzles", NASA Technical Note D-846, 1961.

${ }^{3}$ Campbell C.E., and Farley J.M., "Performance of Several Conical Convergent-Divergent Rocket-Type Exhaust Nozzles", NASA Technical note D-467, 1960.

${ }^{4}$ Crocco L., and Lees L., "A Mixing Theory for the Investigation between Dissipative Flows and Nearly Isentropic Streams", Journal of the Aeronautical Science, Vol. 19, No. 10, 1952.

${ }^{5}$ Donaldson C., and Lange R., "Study of Pressure Rise across Shock Waves required to separate Laminar and Turbulent Boundary Layer", NASA TN 2770.

${ }^{6}$ Dumnov G., "Investigation on Separation and Side Loads", Internal DLR Report, 1997.

${ }^{7}$ Erengil M.E., and Dolling D.S., "Unsteady Wave Structure near Separation in a Mach 5 Compression Ramp Interaction", AIAA Journal Vol.29, No. 5, Page 728-735, 1991.

${ }^{8}$ Farley J.M., and Campbell C.E., "Performance of Several Method-of-Characteristics Exhaust Nozzles", NASA Technical note D-293, 1960.

${ }^{9}$ Foster C.R., and Cowles F.B., "Experimental study of gas flow separation in overexpanded exhaust nozzles for rocket motors", ORDCIT Project, Progress report No. 4-103, 1949.

${ }^{10}$ Frey M., Stark R., Ciezki H., Quessard F., and Kwan W., "Subscale Nozzle Testing at the P6.2 Test Stand", AIAA Paper 2000-3777, 2000.

${ }^{11}$ Frey, M., "Behandlung von Strömungsproblemen in Raketendüsen bei Überexpansion“, Ph. D. Thesis, Universität Stuttgart, 2001.

${ }^{12}$ Frey M., Rydén R., Alziary de Roquefort Th., Hagemann G., James Ph., Kachler Th., Reijasse Ph., Schwane R., Stark R., "European Cooperation on Flow Separation Control", 4th International Conference on Launcher technology "Space Launcher Liquid Propulsion", Liege, 2002.

${ }^{13}$ Girard S., and Alziary de Roquefort T., "Study of flow separation in overexpanded rocket nozzles", 4 th French-RussianItalian-Uzbek Workshop, 1997.

${ }^{14}$ Gross A., Haidn O., Stark R., Zeiss W., Weber C., and Weiland C., "Experimental and Numerical Investigation of Heat Loads in Separated Nozzle Flow", AIAA Paper 2001-3682, 2001.

${ }^{15}$ Hagemann G., Preuss A., Grauer F., Frey M., Kretschmer J., Rydén R., Jensen K., Stark R., and Zerjeski D., "Flow Separation and Heat Transfer in High Area Ratio Nozzles", AIAA Paper 2004-3684, 2004.

${ }^{16}$ Kalt S., and Badal D., "Conical Rocket Nozzle Performanc under Flow-Separated Conditions", Journal of Spacecraft and Rockets, Vol. 2, No. 3, page 447-449, 1965.

${ }^{17}$ Kronmüller H., Schäfer K., Zimmermann H., Stark R., "Cold Gas Subscale Test Facility P6.2 at DLR Lampoldshausen”, 6th Symposium on Propulsion for Space Transportation of the XXIth century, Versailles, 2002. 
${ }^{18}$ Kudryavtsev V.M., "Fundamentals of Theory and Calculations of Liquid Rocket Engines" (in Russian), edited for Moscow High School, 1975.

${ }^{19}$ Kwan W., and Stark R., "Flow Separation Phenomena in Subscale Rocket Nozzles", AIAA Paper 2002-4229, 2002.

${ }^{20}$ Lawrence R.A., "Symmetrical and unsymmetrical flow separation in supersonic nozzles", Ph. D. Thesis, University Dallas, 1967.

${ }^{21}$ Lawrence R.A., and Weynand E. , "Factors affecting Flow Separation in Contoured Supersonic Nozzles", AIAA Journal, Vol. 6, No. 6, page 1159-1160, 1968.

${ }^{22}$ Mager A., "On the model of the Free Shock Separated Turbulent Boundary Layer", Journal of the Aeronautical Science, Vol.23, No. 2, 1956.

${ }^{23}$ McAmic R.W., Lankford D.W., and Phares W.J., "Theoretical liquid rocket engine nozzle flow fields", AIAA Paper 92 $3730,1992$.

${ }^{24}$ Nave L.H., and Coffey G.A., "Sea level side loads in high-area-ratio rocket engines", AIAA Paper 73-1284, 1973.

${ }^{25}$ Östlund J., "Flow processes in rocket engine nozzles with focus on flow separation and side-loads", Licentiate Thesis, Royal Institute of Technology Stockholm, Technical Report 2002:09, 2002.

${ }^{26}$ Reijasse Ph., Morzenski L., Blacodon D., and Birkemeyer J, "Flow Separation experimental Analysis in overexpanded Subscale Rocket-Nozzles", AIAA Paper 2001-3556, 2001.

${ }^{27}$ Schilling M., "Flow Separation in a Rocket Nozzle", M. S. Thesis, Uinv. Buffalo, 1962.

${ }^{28}$ Schmucker R., "Strömungsvorgänge beim Betrieb überexpandierter Düsen chemischer Raketentriebwerke, Teil 1: Strömungsablösung", Bericht TB-7, Tech. Univ. Munich, 1973.

${ }^{29}$ Stark R., Kwan W., Quessard F., Hagemann G,, and Terhardt M., "Rocket Nozzle Cold-Gas Test Campaigns for Plume Investigations", 4th European Symposium on Aerothermodynamics for Space Vehicles, Capua, 2001.

${ }^{30}$ Stark R., Kronmüller H., and Zerjeski D., “Advanced Flow Visualisation Techniques in Cold Gas Subscale Nozzles, a Comparison", AIAA Paper 2003-5180, 2003.

${ }^{31}$ Summerfield M., Foster C., and Swan W., "Flow Separation in Overexpanded Supersonic Exhaust Nozzles", Jet propulsion, Vol. 24, No. 9, page 319-321, 1954.

${ }^{32}$ Sunley H.L.G., and Ferriman V.N., "Jet separation in conical nozzles", Journal of the royal aeronautical socity, vol. 68 , pp.808-817, 1964.

${ }^{33}$ Tagirov R.K., "Calculation of Critical Pressure Ratio in a shock occurred at Turbulent Boundary Layer Separation" (in Russian), AS USSR, MFG, No. 4, 1985.

${ }^{34}$ Takahashi M., Ueda S., Tomita T., Takahashi M., and Tamura H., "Transient Flow Simulation of a Compressed Truncated Perfect Nozzle", AIAA Paper 2001-3681, 2001.

${ }^{35}$ Tomita T., Takahashi M., Takahashi M., Ueda S., and Tamura H., "Visualization of the formation of separation bubbles on a bell-shaped nozzle surface in relation to serious side-load", AIAA Paper 2001-3559, 2001.

${ }^{36}$ Torngren L., "Flow Separation Tests on Several Different Nozzles Suspended in a Universal Joint", F.F.A. Project AU4911, AE-4931.

${ }^{37}$ Tsunoda K., and Suzuki T., "Improvement of the performance of a Supersonic Nozzle by Riblets", Journal of Fluids Engineering, Sep. 2000, Vol. 122, page 585-591, 2000.

${ }^{38}$ Zukoski E., "Turbulent Boundary-Layer Separation in front of a Forward-Facing Step", AIAA Journal, Vol. 5, No. 10, Page 1746-1753, 1967. 